\title{
Strategic Fast Supply Demand-Chains in a Network Context: Opportunistic Practices That Can Destroy Supply Chain Systems
}

\author{
José Crespo de Carvalho*, Ana Lúcia Martins, Tânia Ramos, Eurico Brilhante Dias \\ Professors at ISCTE-IUL-Lisbon University Institute, Lisbon, Portugal \\ Email: ${ }^{*}$ crespo.carvalho@iscte.pt
}

Received 30 January 2014; revised 28 February 2014; accepted 7 March 2014

Copyright $@ 2014$ by authors and Scientific Research Publishing Inc.

This work is licensed under the Creative Commons Attribution International License (CC BY).

http://creativecommons.org/licenses/by/4.0/

\section{Open Access}

\section{Abstract}

This paper has a conceptual character and explores an approach between transaction cost analysis theory and network theory when applied to supply chains in a broader context: industrial management research. This approach raises the assumptions that fast supply chains, i.e., supply chains made of short time relationships and multiple partners can contribute to destroying trust and collaboration between companies, ending up by stressing actual systems' arrangements in somehow stable supply chains/network chains. As a consequence, transforming them in distrust arrangements and thus giving birth to new (old) approaches based only on transaction cost analysis theory: opportunism and limited rationality as the continuum for relationships between companies in a globalized world with numerous potential agents/companies that can play several roles. Too high levels of entropy can show this reality: the number of potential players (suppliers, customers or complementors) with theoretically equal probability of establishing partnerships with one focal company in a supply chain or network arrangement is excessive in relation to the number of current suppliers, customers and complementors, and for that reason, the focal company is somehow dissipating energy in identifying several potential players and in a state of giving one way or another equal importance to them all, situation that can affect stable relations with current partners. Theoretically, this will create what looks like strategic fast supply-demand chains or network chains: fast because they are rapidly settle down and fast as they are also rapidly dismantled. Those arrangements are the ones responsible for several possible and fast relations (internalizing resources from the environment and/or externalizing resources to the environment) but, anyway, contributing to loose trust, credibility and running against profitable games with partners already involved with focal companies in stable supply chains.

*Corresponding author. 


\section{Keywords}

\section{Strategic Fast Supply Chains; Network Chains; Opportunism; Collaboration}

\section{Methodology}

The exercise developed throughout this paper is to briefly review systems theory, applications and implications to industrial management and, once having a general frame that serves as a basis for thinking and conceptually concluding, explaining the consequences of strategic fast supply-demand chains as possible destructive arrangements for stable relationships, collaborative planning and profitable games for all the participants in a supply or network chain configuration. Within this frame (system theory, largely disseminated in the industrial management community) one may emphasize the importance of a certain degree of stability and trust and analyse the consequences of having a value of entropy (high value of entropy) that exposes an high and equal probability of having several potential relationships between a focal company and other latent participants (being suppliers, clients—remembering that good clients are not all the possible clients—or complementors) in a supply chain.

The point of this paper is thus the preoccupation that focal companies overly focused in enlarging relationships and arranging possible suppliers, clients and complementors may give birth to an excessive interactive basis, becoming vulnerable, in consequence, to opportunistic games and, thus, forgetting the importance of relationship stability.

The methodology approach is totally conceptual and interpretative/qualitative. The authors reviewed some literature that came from system theory and interpreted the degree of entropy related with a system of companies and its focal company, or the company one intends to study, and understand, when inserted in a supply chain/network of companies, namely when the entropy tends to be high. High entropy values may show arrangements composed by a large number of potential companies, as partners, and eventually signalling the trend to a focal company to participate in strategic fast supply-demand chains and, in consequence, to lose the ability to stabilize partnerships and to profit from deep relations, trust and joint work.

\section{Introduction}

Jay W. Forrester made the first approach to a management problem that explicitly claimed to rely upon system's theory in the late fifties [1]. The inventory "ups and downs" suffered by the General Electric household appliances plants in Kentucky were then explained using a computer model developed in accordance with the principles of systems control theory [2]. The methodology was initially called industrial dynamics, before its general character made it known as system dynamics.

One of the major impacts of Forrester's work was the recognition that only system approaches could provide a deep insight on complex dynamic behaviours such as the bullwhip effect [3] [4]. The network configuration of today's supply chains in the context of industrial management with an ever-increasing number of partners, each one following its own strategy and taking actions that do not always fit with the common objectives, the fuzzy nature of many of their inter-relationships, and the dynamic character of all the variables impose a system approach if one looks for an effective network management (SCM) or the activation and management of beneficial relationships (at least) with suppliers [5]-[7] but, also, with clients and complementors, if not with competitors [8] [9].

Thus, if network constraints and potentials may open enormous opportunities to explore some type of supplydemand organizations and its arrangements and, also, to discover new flexible and adaptable businesses in order to survive, systems theory may be very helpful in structuring the theoretical background for networks and in conducting the whole approach. In fact, one should structure the network approach having in mind the contributions of Doz and Hamel [10], Gadde and Håkanssson [11] and Gadde, Håkanssson and Pearson [7], and the enormous contributions of the IMP group (Industrial Marketing and Purchasing Group-Network Theory) [12], among others, or one should follow systems theory when considering the dynamic character of all variables in a supply-demand chain or even in a network of supply-demand chains.

If no single company can succeed by itself, thus being required to work in partnership, one may argue that 
stable alliances are not unique answers to this modern wave of win-win collaboration, meaning positive shared achievements. As a result, if networks are becoming the rule, a way to govern complexity and to organise companies, then some conceptual development has to be done over them in order to explain fast engagements and rapid dissociations or the occurrence of more and more quick collaborations.

Systems theory can additionally explain this trend to multiple liaisons and complex arrangements that characterize certain focal companies that, being rapid in engagements and dissociations are, also, and that is the other face of the this coin, contributing to non-stable collaborations and systems' disruption. The disruption of such systems - supply chains or network chains - are, thus, motivated by this quiver of multiplying contacts that, hypothetically, allow focal companies to enlarge knowledge and, indirectly, profits. At the very end, it will be resumed as, somehow, a back to basics: these focal companies are being a prey of opportunism and short term profit willingness.

The purpose is, then, to develop and present a strategic fast supply-demand chain configuration having in mind systems theory and logistics and supply chain management (SCM) principles. Thus, the paper will focus on five main issues in order to explore strategic fast supply-demand chain arrangements (sometimes authors are using flexibility as the argument for supply chains and not recognising that flexibility leads to fast access and fast disintegration of supply chains [13]: 1) main aspects of systems theory and relations with SCM; 2) strategic fast supply-demand chains created over broad network contexts; 3) types of companies interested in strategic fast supply-demand chains or fast network chains, with short times for creation and also for destruction of such chains/networks; 4) finally, some conclusions.

\section{Systems Theory and Supply Chain Management}

Scientific methods based on cartesianism and reductionism, so successful in the physical sciences, first came across its limitations and drawbacks in biology. The modern concept of system, formulated around 1930 by von Bertalanffy—following previous works by Leduc and Bogdanov [14] — spread out to all fields of knowledge and became the current scientific paradigm.

Systems' theory focus the problems raised by complex entities that are perceived as a whole-i.e., that are more than just the sum of its components - and exhibit properties that cannot be derived from its parts. Among the main features that most systems share is important to emphasise [15] [16]: 1) every system has a structure, which is the set of its components plus the set of rules defining their interrelationships; 2) every system has a teleological character, i.e., is driven towards a set of goals, which is equivalent to say that every system has a purpose; 3) every system interacts with its environment, performing activities that change the system's state in order to approach the established goals. In the course of this evolution and due to the presence of feedback loops, the system's structure, the set of goals and the environment change continuously. A system that interacts with its environment, influencing it, is said to be an open system. And yes, a system can be defined also by a boundary between itself and its environment which can be seen as a complex concept of a system [17]. Complexity, however, is perhaps the most common characteristic of a particular system, namely when referring to social and organizational open systems.

Two types of complexity are usually present in a system: 1) detail complexity and 2) dynamic complexity. Detail complexity occurs when the system has a large number of components and is related to the difficulty the human brain has in dealing with many variables at the same time. Dynamic complexity has a different character and is a consequence of the system's structure. It is related to the ability that systems have to exhibit emergent behaviours, i.e., dynamic changes in their states that cannot be derived from the parts, but are a property of the whole. They can only be understood if one looks at the system's structure, namely at 1) the causal loops originated by feedback, 2) the time delays that occur between an action and its effect, and 3) the non-linear character of most relationships.

These properties are the main causes for dynamic complexity: in a linear process, inputs are transformed in outputs and, whenever time effects are present, outputs are separated from inputs by a time interval; past influences the present [18]. In more complex processes, however, the result of an action causes, usually after a time delay, modifications of the pre-existing conditions that determined that action. Information about the output is fed back to the system as a new input, leading to a corrective action that changes the output (once again after some delay). A simple cause-effect relationship is then replaced by a causal feedback loop-which introduces a non-linearity. 
Time delays, feedback loops, fuzzy variables and dynamic environments are features easily recognised by everyone in today's businesses and in industrial management. They are the root causes for the bullwhip effect and plenty of other counterintuitive behaviours presented by social systems [19] [20]. It is thus not surprising that system approaches are now commonly recommended and used in many situations and, particularly, in industrial management [6] [21]-[23].

The model is another concept that is important to highlight, when one starts to look for ways of developing a system approach. The concept of model is so strongly linked to the concept of system that Le Moigne considers the theory of the general system as the theory of modelling [16].

A model is a simplified representation of a system that is useful for solving a problem. Or "the purpose of a simulation model is to mimic the real system so that its behavior can be studied” [24]. And, as many authors refer, the model's development is driven by the search of a solution to the problem to be solved [6] [25].

The general availability of computers and their ability to easily store and process large amounts of information, and solve thousands of interrelated equations-particularly relevant when someone is dealing with social systems - offer a cheap and powerful way to develop system models and simulate the system's behaviour in a wide range of different scenarios.

The outcome of a consistent set of simulations can be a forecast, as in the case of econometric models, the evaluation of the impact on the system of different environment conditions or internal decision policies, or the outcome of different strategies. Furthermore, through simulation, some unexpected behaviour can be identified and understood, and new policies can be designed to prevent them [19] [26].

This background provides the reasons why systems thinking, computer models and simulation are increasingly used as an aid to solve industrial management problems.

It was in the management of large modern engineering projects—starting with the military projects launched in the first years of the cold war, that the high levels of complexity first made unavoidable a system approach. The trend widened soon to other fields, following the systems thinking movement launched by Ackoff and pursued by many others like Jackson [27] until more recent attempts to "manage at the edge of chaos" with Stacey [28]. Important contributions came also from Beinhocker [29], Brown et al. [30] and Khun [31], among many others.

Genetic algorithms, cellular automata, evolutionary game theory, fuzzy-logic, agent-based models, real options, soft systems methodologies and system dynamics are some of the methodologies and tools developed in the last years to deal with complexity and that have application in economics and industrial management.

Applications range from executive training, design of robust decision policies, evaluation of strategic options, support to change management processes, and the development of the "learning organisation" [32] [33].

The acceleration suffered by the economy and the business activity during the last years only reinforced the need for system thinking and for system approaches to many of the industrial managers’ problems.

Today, using different technologies anyone can communicate directly to anyone, anywhere, and people and goods can move from a continent to another in a matter of a few hours. Every branch of specialised knowledge is freely available to anyone who has access to the Internet.

All this evolution took place at an increasingly quick pace. A century ago, sailing ships made most of the sea trade; forty years ago propeller airplanes offered travel possibilities at an almost unbearable price; twenty years ago the telex was the standard technology available for rapid transfer of information between two companies.

Any industrial manager who envisages staying in business has to be flexible and adapt his company to all these changes, and has to do it very fast, in spite of the volatility of exchange rates and oil prices, and the crushing pressure of the financial markets.

The days when a company like Ford could transform, in a single plant, coal and iron into cars are over, as The Economist [34] remarked. Focus on the core business and outsource everything that someone else can do better and cheaper became the dominant trend and a rule of the game.

Opponents to this trend, especially when outsourcing involves the participation of external countries that welcome externalized operations, paved also their way and thoughts. With extreme degrees of externalization, unemployment levels will rise just because companies are trying to find locations with low cost factors, losing nationality pride and exhibiting, also, high opportunism levels [35].

However, in our times of globalisation of economies, markets and knowledge, it seems that the boundaries of the firm are fuzzy, the extended enterprise appears as the new industrial paradigm, and supply chain management is recognised, if not yet logistics network management [36], as an important piece of corporate strategy 
[37]-[39].

Making the fundamental strategic "make-or-buy" decision is increasingly tough, when economies and businesses compete in a global economy, with competition going in parallel with cooperation: two fierce competitors in one market must cooperate in another one, if they want to succeed. Buyers and sellers look for alliances and become business partners. Sell and buy on a point basis is replaced by outsourcing, and the management of the value system replaces the management of the value chain (beginning, somehow, with Hines [40]). As stated by Fine [41], "the ultimate core competency of an organization is 'supply chain design', which I define as choosing what capabilities along the value chain to invest in and develop internally and which to allocate for development by suppliers". Thus, managing a business becomes indissociable of the management of the partners' network and managing a supply chain indissociable of people and their capabilities [42].

A network is a complex system of entities and relationships, processes and flows, and therefore cannot be managed, or at least it is difficult, without relying upon a system approach, either at a strategic or at an operational level.

The reason for this arises, in part, from the large number of partners and other stakeholders, each one with its own set of objectives, the huge amounts of data, the multidisciplinary expert knowledge needed, and the frequent novelty of the situations that are present in SCM.

However, internal dynamic complexity is usually more relevant: linear processes and simple one-to-one relationships are not the rule anymore. Multiple choices, bifurcating paths, conflicting goals, information feedback, variable time delays, and other elements that originate non-linearities are part of the daily life of today's industrial manager. And, since the effects of all these are amplified by the dynamics of the external environment, the complexity of each problem in SCM tends always to rise. In such a situation only a consistent model and simulation can efficiently help to find a solution.

Additionally, one can use systems theory and, particularly, the concept of entropy to foresee the state of the system and the respective focal company object of analysis. High levels of entropy usually mean high complexity and propensity to unstable relations and multiple potential partners: strategic fast supply-demand chains, fast relations accompanied by rapid creation and disaggregation arrangements. These can give origin to supply chain systems disruption and multiple unstable interactions. Complexity will be, however, the rule of the game.

In these circumstances, the portfolio of problems that can be solved with simulation is almost unlimited and only a very brief outline can be presented here.

At an operational level, resource allocation, co-ordination of inventory decisions and transportation decisions, and matching supply and demand are some of the problems in SCM usually covered by textbooks [5] [37] [43] [44] that are easily perceived as requiring a system approach. Models can provide the basis for answering "what-if" questions through simulation, and for finding robust theories and decision policies [45].

Distribution strategies, network configuration, organisation design, supply chain integration, strategic alliances and information systems design are some of the strategic decision making processes where a powerful set of methodologies and techniques using scenario planning and simulation can offer a valuable contribution.

Many other approaches are reported in the literature, covering matters like the supply chain dynamics [46]-[49], partners' management [50], performance analysis [51], decision policies [52], and integration of product management with order strategies [53] and with several intersections with industrial management.

With so many directions and installed capacity one should try to frame, at the conceptual level, this strategic fast supply-demand chains movement, created over broad network contexts. Systems theory may help in the reasoning because the focus is concentrated upon systems dynamics instead of being in systems stability or long term collaboration, ideal conditions to compel directional and somehow crystallized (and somehow undesired) supply chains (the ones that present an entropy tending to zero and originated by an excess of stability and a number of potential partners practically equal to the current ones, being companies too static for the right level of market dynamics needed).

\section{Strategic Fast Supply-Demand Chains}

One can find, at a large scale, several companies developing multiple actions in various activity sectors and, also, with diverse business typologies. Therefore, there is a company universe that can be considered statistically endless. If each one of the companies of the entire universe decides to collaborate with the others the potential number of relations could tend also to be endless. Thus, it is better-and more realistic - to consider the exis- 
tence of a global business system including the companies' universe and multiple business sub-systems whose companies may establish more or less stable relationships between themselves.

It is known that companies collaborate to reach alternative markets, to complete product lines or services, to achieve synergetic effects in operations and marketing, to win critical mass in purchasing, to centre themselves in the core business or to transform fixed costs into variable costs, among others.

Arrangements that emerge from simple partnerships have become, for the same markets and for various products/services typologies', more like networks of opportunities but also of threats, in a global world, and considered, somehow, an asset or a barrier to work with trust, collaboration and joint planning. The level of opportunities is as big as the number of potential partners. However, there is always a reverse side in all these opportunities. If a focal company wants to profit from all the opportunities it will certainly become blind in terms of the current partnerships. The need to go deeper in actual opportunities is, however, probably more important than to explore the all set of possible partners and relations. This blindness corresponds to an increasing degree of opportunism, being the result the lack of trust and stability needed to accompany profitable partnerships and supply/network chains.

The truth is that instruments and contact tools and possibilities between companies and suppliers, for instance, only came to "aggravate" that tendency. e-Procurement tools and all the automation of the suppliers' qualification processes are an example of that. The easiness one can do procurement is, nowadays, greatly amplified; hence, a stable relation upstream can easily be questioned by a straightforward discovery of more interesting alternative suppliers (substitutes), being geographically distant but very close in informational terms. Attractive, from one perspective, but delicate from another perspective. Just because they install the tremor of having more and more partners as if more means more profit, more stability and more accurate supply chains. More can mean, in this case, less stable relations, mistrust and the collapse of a collaborative spirit.

The downstream CRM practices should eventually lead to bigger customer loyalty. Although, nowadays it is known that market share can come precisely through the share of wallet—or client share accumulation. Even so, the client has become less oriented to loyalty, in a global world, because experiences, hypothetically, add more value — both personal and professional—-than products or services or even transactions. Experiences are, then, obtained through several products, services and events combinations' (Service Dominant Logic, S-D Logic, instead of a Goods Dominant Logic-G-D Logic) [54]-[59].

These facts arise serious problems to supply chains that, when not being configured with a certain degree of stability, for determined market demands, may become more and more dynamic and close to a rapid end. These situations occur when trying to offer a new experience facing the perception of a new or differentiated client exigency/requirement/need.

In these circumstances, both upstream and downstream, it can be verified bigger relational volatility than the one presented and defended by network theory. This can lead to increase the degree of opportunism, one of the main characteristics of transaction cost analysis theory. Transaction cost analysis (TCA) assumes that economic relations between two parties follow predictable patterns, resulting in attempts to optimise the economic benefits for each party in the relationship, i.e., each party involved in a relation seek to optimise their own benefit from the relationship because the costs of building deep relationships are usually higher than a win-loose (ad-hoc) liaison.

One cannot say, peremptorily, that network's principles are, nowadays, driving completely business models and rising collaboration as an organization principle. The fact is that time and resource scarcity (crisis periods like the one the all world is living now, with financial and economic turmoil's) can lead to more core business approaches/developments, among others, and deep partnership progresses and, also, protection. Albeit, there is an increase in empirical aspects that show hybrid, if not totally individual behaviours and opportunistic approaches, that came also with the crisis and that cannot be excluded: 1) agent's limited rationality; 2) agents' opportunistic actions (TCA); 3) necessity of risk neutralization (TCA); 4) tendency to opportunistic collaboration and strategic fast supply-demand chains/networks creation (new disruptive paradigm?).

The coexistence of the network theory, as a business paradigm, along with the transaction cost analysis theory, authors believe, and in a context of worldwide crisis, allowed the evolution of this reasoning in the industrial engineering area, i.e., focused on strategic fast supply-demand chains: 1) collaboration is opportunistic itself; 2) agents are always keen to earn from several different experiences, usually possible due to the partnership accumulated knowledge, namely when a new/diverse market demand happens; 3) the hierarchical control (vertical integration) used in the transaction cost analysis theory, in order to minimize risk of opportunistic behaviour, 
was transformed in the network information control (rapid informational integration capacity), that should allow the accumulation of a set of experiences and to normally accept the change as a management component; 4) systems theory is, after all, the theory that better explains -in practice-when a company is close of integrating a strategic fast supply-demand chain because of the entropy degree it develops as a focal company.

Within this scenario one can easily understand why companies are asking to participate in supply chains that will provide them, theoretically, knowledge and various experiences: 1) visibility in the sense of awareness; 2) multiple contacts with diverse suppliers, clients and complementors, eventually developing knowledge; 3) entry in new geographic disperse markets; 4) informational interface standardization and information homogeneity; 5) new (theoretically) capabilities creation; 6) cost (wishful thinking) rationalization; 7) business virtualisation and fixed cost reduction; and 8) accumulated relational capacity and experience; among others.

In this sense some companies will have to be familiar with, and looking for, the integration in strategic fast supply-demand chains. Is this movement wise? Companies can face eventually huge benefits, like the ones previously (and controversially) described. In fact, fast supply-demand chains may rise the worst in industrial management environments: opportunism, limited rationality, isolationism, the sense of controlling everything and every player and that the large spectrum of potential relations are creating knowledge and profitable ways to approach business models. In a word, fast supply demand chains can isolate companies again and reintroduce price based discussions, adversarial relationships and several potential suppliers in an open market negotiation, characteristics of the old days of industrial engineering environments.

\section{Types of Companies Interested in Strategic Fast Supply-Demand Chains}

Central companies to strategic fast supply-demand chains are those fighting to accumulate hypothetical knowledge and collect relational capabilities. Relational capability is achieved through contact increasing and, also, through experience development. For this reason companies may be classified as being central or peripheral, when analysed, according to the level of accumulated knowledge (meaning the number of contacts and associated knowledge). Conceptually, they will be more central when more experiences and knowledge accumulation can be demonstrated and more peripheral when the opposite happens. Therefore, the centre or the peripheral character of a company cannot be measured, today, only through the origin or location in terms of geographic area but, also, through the bridges they are or are not able to build with other companies and agents throughout the world, namely benefiting from information and communication systems and technologies.

Nonetheless, this centrality can be artificial, as the peripheral character is. Is knowledge derived from several relations or from going down, deeper and deeper, in a relation? And, of course, being prepared to change if necessary? The knowledge suffers, somehow, from different perspectives: it can be gained by the number of different experiences and relations one company develops but, in another way, it is for sure far richer if those relations can go deeper into the full trustiness and openness between companies/partners. This requires time, investment and stability. Exactly the contrary to several "touch and go" relationships or fast supply demand chains. So, the secret seems to be having good sense, meaning with this that there are virtues in collecting different experiences but also virtues in developing long term partnerships, trust and stability. In industrial management, and generally in management, theory, common sense seems to be the most valued asset.

Who has common sense and who hasn't? What is really common sense? Is that common sense so important to industrial management and management in general? As in all aspects of life, common sense is a basic ability to notice, comprehend and judge things which is shared by almost all people and having with no need for questioning. The expression, in this case, is the one with Roman roots (not the Aristotelian common sense) and it is used to explain the natural human sensitivity for other humans and the community. Just like the everyday meaning, common sense refers to a type of basic awareness and ability to judge which most people are expected to share naturally, even if they cannot explain properly why.

And how about the final market? Will it be able to be served with stability and long term relationships? Or, at the contrary, it will only be served by a hunting feeling and an accumulation of short term partnerships, basically the same behaviour as a hidden opportunism. As in several other areas of management, the answer that seems to be more accurate is the one that encapsulates gumption. Final markets will be better served with an approach that may collect knowledge that comes not only from the thrill of having more and more experiences but also from the capability of conserving and feeding established partnerships, that can be fed by confidence, respect, mutual sharing, joint planning, and, at the very end, true collaboration. 
This means that somehow, and in the light of systems theory, one should ask for a degree of entropy, in companies, not close to zero. Because if entropy tends to zero the focal company may be totally crystalized and, eventually, the participation in future supply chains has not been considered, which can be an obstacle to a certain degree of dynamics. On the other hand, if entropy is high the focal company is totally compelled to enlarge the number of potential partners, rising the levels of complexity and entropy. This type of movement, the thrill for relationship accumulation, may cost the continuity of the existing partnerships and the stability of the current ones, jeopardizing appropriate relationships and trust.

When using Shannon and Weaver's [60] work (related with information theory but adapted, here, to the propensity to accumulate probability of contacts) to define entropy, a transposition to companies can be done when using its own entropy coefficient. In this context, entropy means the higher or lower probability with which certain relationships can occur between the company and its potential suppliers, clients and/or complementors.

If entropy is high and all the events (and relationships) have practically the same probability of happening for a focal company, when it belongs to a certain supply chain/network chain, then the accumulation of experiences can be dangerous in terms of stability and creation of real collaborative approaches. If entropy tends to zero the company is crystalized in the actual collaboration environments and not prepared to change, if necessary. These 'extreme' scenarios are actually not very interesting in terms of having an equilibrium between different relationship experiences and nurturing and feeding stable relations in order to have some medium to long term ones and trust, which actually means having "common sense" management practices.

Thus, entropy measures the amount of uncertainty of an unknown or random quantity. Having this in mind and also the work of Shannon and Weaver [60] the entropy of a random variable $\mathrm{X}$ is defined as being:

$$
\mathrm{E}(\mathrm{X})=-\sum_{\mathrm{i}=1}^{\mathrm{K}} \mathrm{p}(\mathrm{x}) \times \log _{2} \mathrm{p}(\mathrm{x})
$$

where the sum is over all the $\mathrm{x}$ values that the variable $\mathrm{X}$ can take (all the companies present in all the activity sectors, or the $\mathrm{K}$ value, with which the focal company can establish partnerships). $\mathrm{p}(\mathrm{x})$ is the probability of each of these values occurring. Entropy can be measured as the degree of propensity of a focal company to possible connexions, establishing equal probabilities to every potential company to become a partner of the focal one. With a low entropy value there are no prospect connections apart from those already established, if any. With a high (positive) value there is an accumulated propensity to establish relations with potential suppliers, clients and complementors (if not, additionally, with competitors).

As one can see the tendency to maximum entropy is probably a tendency to the system disorder and the failure of one or more supply chain/network members with the collapse of the all supply-demand chain. Strategic fast supply-demand chains are probably the threshold to the general supply chains systems failure and to the end of a network perspective. So to say, a new order with multiple opportunistic relations may give birth to a new paradigm but it also eventually dictates the general failure of stable partnerships and can pave the way to distrust and also to the collapse of what was intended with supply chain arrangements and networks: trust, collaboration, joint planning, open and collaborative systems, shared technology and general players openness and adaptability in order to better serve markets.

Fast supply-demand chains, in practical terms, can constitute a tendency to reverse supply chains and to bring back old days of suspicion, mistrust and open markets practices (spot markets and bidding negotiations), even before supply chain or relational approaches intensification and collaborative games started to be common. However, if a paradigm in terms of relations between companies, fast supply-demand chains paradigm, can be adversarial to the establishment of stable supply chains and if the development of established and long term supply chains may, consequently, be threatened, then one can say that probably this eventually new paradigm is destroying the previous one and reversing the reality to old days when larger and unfocused companies where playing isolated games and open market negotiations.

Consequently, there is no such thing as a new paradigm because, in the very end, the old paradigm is more than alive, i.e., transaction cost theory has been reinvented and price based discussions and adversarial relationships came again to the stage. All this expressed by zero sum games and different approaches to opportunism: an encapsulated form of collaboration that brings back short term relationships, or no relationships at all. Only spot and occasional relationships.

Through this line of reasoning, and regarding the focal company as an open system with an hybrid behaviour character between transaction cost theory and network theory, one can go through with the assumption that stra- 
tegic fast supply-demand chains are more frequent in activity sectors with multiple players and high competitive pressures ( $1^{\text {st }}$ factor); within the proximity of final markets (consumer oriented markets) $\left(2^{\text {nd }}\right.$ factor); in intensive I\&D sectors ( $3^{\text {rd }}$ factor); and between companies with strong dependence of information and communication systems and technologies ( $4^{\text {th }}$ factor).

These types of assumptions can be exemplified with several empirical data. However, the point of this paper, as already stated, is thus the preoccupation that focal companies overly focused in enlarging relationships and arranging possible suppliers, clients and complementors (or even competitors) may give birth to an excessive interactive basis, becoming vulnerable, in consequence, to opportunistic games and, thus, forgetting the importance of relationship stability.

\section{Conclusion}

Three major conclusions, followed by a question, should be, at this stage, intensively addressed: 1) Transaction Cost Analysis (TCA) Theory assumptions should be used and remembered even if the moment apparently favourites Network Theory approaches; however, one must be acquainted with the worldwide crisis that is revealing, again, opportunism characteristics and blind company practices in order to survive at any cost; 2) Systems Theory (and Industrial and Systems Dynamics [25] [61]), because of its nature, will certainly represent an ideographic approach to help further developments and to explore the benefits and pitfalls of this new strategic fastdemand supply chains/network chains; 3) Formal and empirical studies should be carried out in order to validate assumptions and to identify the keys, and to isolate the leverage mobiles, to create these strategic fast supplydemand chains; 4) Finally, the question that should help future reasoning should be posed in this terms: Is knowledge (society) more aligned with strategic fast supply-demand chains and relationship accumulation and experiences or with traditional and stable supply chains? Or, as the authors stated, at the very end what is determinant is the industrial management "common sense" applied to all the situations.

\section{References}

[1] Forrester, J.W. (1959) Advertising: A Problem in Industrial Dynamics. Harvard Business Review, 36, 100-110.

[2] Forrester, J.W. (1958) Industrial Dynamics: A Major Breakthrough for Decision Makers. Harvard Business Review, 36, 37-66.

[3] Lee, H.L., Padmanabhan, V. and Whang, S. (1997) The Bullwhip Effect in Supply Chains. Sloan Management Review, 1997, 93-102.

[4] Shahabuddin, S. (2012) The Bullwhip Effect: Is There a Solution? The Business Review, Cambridge, 20, 30-36.

[5] Simchi-Levi, D., Kaminsky, P. and Simchi-Levi, E. (2000) Designing and Managing the Supply Chain-Concepts, Strategies, and Case Studies. McGraw-Hill, Irwin, Boston.

[6] Sterman, J.D. (2000) Business Dynamics: Systems Thinking and Modeling for a Complex World. McGraw-Hill, Irwin, Boston.

[7] Gadde, L.-E., Håkansson, H. and Persson, G. (2010) Supply Network Strategies. 2nd Edition, John Wiley \& Sons, Hoboken.

[8] Brandenburger, A.M. and Nalebuff, B.J. (1997) Co-Opetition. Currency Doubleday.

[9] Yami, S., Castaldo, S., Dagnino, G.B. and Le Roy, F. (2010) Coopetition: Winning Strategies for the 21st Century. Edward Elgar Publishers. http://dx.doi.org/10.4337/9781849807241

[10] Doz, Y. and Hamel, G. (1998) Alliance Advantage: The Art of Creating Value through Partnering. Harvard Business School Press, Boston.

[11] Gadde, L.-E. and Håkansson, H. (2001) Supply Network Strategies. John Wiley \& Sons, Hoboken.

[12] Industrial Marketing and Purchasing Group (2014). http://www.impgroup.org/

[13] Singh, R.K. and Sharma, M.K. (2014) Prioritising the Alternatives for Flexibility in Supply Chains. Production Planning \& Control, 25, 176. http://dx.doi.org/10.1080/09537287.2013.782951

[14] Bertalanffy, L. (1968) General Systems Theory. Penguin Books, London.

[15] Kast, F.E. and Rosenzweig, J.E. (1972) General Systems Theory: Applications for Organization and Management. Academy of Management Journal, 1972, 447-466. http://dx.doi.org/10.2307/255141

[16] Le Moigne, J.L. (1977) La Théorie du Système Général: Théorie de la modélisation. Presses Universitaires de France, Paris. 
[17] Luhmann, N. and Gilgen, P. (2012) Introduction to Systems Theory. Polity.

[18] Richardson, G.P. (1999) Feedback Thought in Social Science and Systems Theory. Pegasus Communications, Waltham, Mass.

[19] Forrester, J.W. (1971) Counterintuitive Behavior of Social Systems. Technology Review, 73, 52-68.

[20] Paik, S.-K. and Bagchi, P.K. (2007) Understanding the Causes of the Bullwhip Effect in a Supply Chain. International Journal of Retail and Distribution Management, 35, 308-324. http://dx.doi.org/10.1108/09590550710736229

[21] Checkland, P. and Scholes, J. (1999) Soft Systems Methodology in Action. John Wiley \& Sons, Hoboken.

[22] Gharajedaghi, J. (1999) Systems Thinking-Managing Chaos and Complexity. Butterworth Heinmann.

[23] Lindskog, M. (2012) Systems Theory: Myth or Mainstream. Logistics Research, 4, 63-81. http://dx.doi.org/10.1007/s12159-011-0062-9

[24] Sterman, J.D. (1991) A Skeptic’s Guide to Computer Models. In: Barney, G.O., Ed., Managing a Nation: The Microcomputer Software Catalog, Westview Press, Boulder, 209-229.

[25] Forrester, J.W. (1961) Industrial Dynamics. MIT Press, Cambridge, Mass.

[26] Simon, H.A. (1981) The Sciences of the Artificial. 2nd Edition, The MIT Press, Cambridge, Mass.

[27] Jackson, M.C. (1999) Towards Coherent Pluralism in Management Science. Journal of the Operational Research Society, 50, $12-22$.

[28] Stacey, R.D. (1995) The Science of Complexity: An Alternative Perspective for Strategic Change Processes. Strategic Management Journal, 16, 477-495. http://dx.doi.org/10.1002/smj.4250160606

[29] Beinhocker, E.D. (1997) Strategy at the Edge of Chaos. The McKinsey Quarterly, 1, 24-39.

[30] Brown, S.L. and Einsenhardt, K.M. (1998) Competing on the Edge. Harvard Business School Press, Cambridge, Mass.

[31] Khun, L. (2009) Adventures in Complexity: For Organizations near the Edge of Chaos. Triarchy Press Ltd.

[32] Senge, P.M. (1990) The Fifth Discipline: The Art and Practice of the Learning Organization. DoubleDay Currency, New York.

[33] Kline, P. and Sunders, B. (2010) Ten Steps to a Learning Organization. Great River Books. 2nd Edition.

[34] The Economist (2002) Incredible Shrinking Plants.

[35] Lynn, B.C. (2006) End of the Line: The Rise and Coming Fall of the Global Corporation. Crown Business.

[36] Crespo de Carvalho, J. (2001) E-Business \& E-Commerce-On \& Offline. Edições Sílabo, Lisbon.

[37] Gattorna, J.L. and Walters, D.W. (1996) Managing the Supply Chain: A Strategic Perspective. MacMillan, London.

[38] Sehgal, V. (2011) Supply Chain as Strategic Asset: The Key to Reaching Business Goals. Wiley, Hoboken.

[39] Oliveira, F. and Gimeno, A. (2014) Supply Chain Management Strategy: Using SCM to Create Greater Corporate Efficiency and Profits. IBM Press, Indianapolis.

[40] Hines, P. (1993) Integrated Materials Management: The Value Chain Redefined. The International Journal of Logistics Management, 4, 13-22. http://dx.doi.org/10.1108/09574099310804920

[41] Fine, C.H. (2000) Clockspeed-Based Strategies for Supply Chain Design. Production and Operations Management, 9, 213-221. http://dx.doi.org/10.1111/j.1937-5956.2000.tb00134.x

[42] Gattorna, J.L. (2010) Dynamic Supply Chains: Delivering Value through People. Financial Times Press, Upper Saddle River.

[43] Christopher, M. (1992) Logistics and Supply Chain Management. Pitman Publishing, London.

[44] Christopher, M. (2011) Logistics and Supply Chain Management. Financial Times Series, 4th Edition, Financial Times Press, Upper Saddle River.

[45] Mena, C., Humphries, A. and Choi, T. (2013) Toward a Theory of Multi-Tier Supply Chain Management. Journal of Supply Chain Management, 49, 58-77. http://dx.doi.org/10.1111/jscm.12003

[46] Swaminathan, J., Smith, S.F. and Sadeh, N.M. (1998) Modeling Supply Chain Dynamics: A Multiagent Approach. Decision Sciences, 29, 607-632. http://dx.doi.org/10.1111/j.1540-5915.1998.tb01356.X

[47] Fukunaga, Y., Takahashi, Y., Tanaka, N., Kojima, T. and Morita, M. (2000) System Dynamics Analysis of Stability during Non-Equilibrium Stage in Physical Distribution. Proceedings of the 18th International Conference of the System Dynamics Society, Bergen, 6-10 August. http://www.systemdynamics.org/conferences/2000/index.htm

[48] Groothedde, B. (2000) Dynamics in Spatial Logistic Chains. Proceedings of the 18th International Conference of the System Dynamics Society, Bergen, 6-10 August. http://www.systemdynamics.org/conferences/2000/index.htm

[49] Anderson Jr., E.G., Fine, C.H. and Parker, G.G. (2000) Upstream Volatility in the Supply Chain: The Machine Tool 
Industry as a Case Study. Production and Operations Management, 9, 239-251. http://dx.doi.org/10.1111/j.1937-5956.2000.tb00136.x

[50] Sobrero, M. and Roberts, E.B. (2002) Strategic Management of Supplier-Manufacturer Relations in New Product Development. Research Policy, 31, 159-182. http://dx.doi.org/10.1016/S0048-7333(00)00157-8

[51] Cakravastia, A. and Diawati, L. (1999) Development of a System Dynamic Model to Diagnose the Logistic Chain Performance of Shipbuilding Industry in Indonesia. Proceedings of the 17th International Conference of the System Dynamics Society, Wellington, 20-23 July. http://www.systemdynamics.org/conferences/1999/PAPERS/

[52] Strohhecker, J. (2000) Supply Chain Management: Software Solutions, versus Policy Design. Proceedings of the 18th International Conference of the System Dynamics Society, Bergen, 6-10 August. http://www.systemdynamics.org/conferences/2000/index.htm

[53] Barlas, Y. and Aksogan, A. (1996) Product Diversification and Quick Response Order Strategies in Supply Chain Management. Proceedings of the 14th Conference of the International System Dynamics Society, Cambridge, 22-25 July, pp. 47-50.

[54] Vargo, S.L. and Lusch, R.F. (2004) Evolving to a New Dominant Logic for Marketing. Journal of Marketing, 68, 1-17. http://dx.doi.org/10.1509/jmkg.68.1.1.24036

[55] Vargo, S.L. and Lusch, R.F. (2006) Service-Dominant Logic: What It Is, What It Is Not, What It Might Be. In: Lush, R.F. and Vargo, S.L., Ed., The Service-Dominant Logic of Marketing: Dialog, Debate, and Directions, M. E. Shape, New York, pp. 43-56.

[56] Vargo, S.L. and Lusch, R.F. (2008) From Goods to Service(s): Divergences and Convergences of Logics. Industrial Marketing Management, 37, 254-259. http://dx.doi.org/10.1016/j.indmarman.2007.07.004

[57] Vargo, S.L. and Lusch, R.F. (2008) Why “Service”? Journal of the Academy of Marketing Science, 36, 25-38. http://dx.doi.org/10.1007/s11747-007-0068-7

[58] Vargo, S.L. and Lusch, R.F. (2008) Service-Dominant Logic: Continuing the Evolution. Journal of the Academy of Marketing Science, 36, 1-10. http://dx.doi.org/10.1007/s11747-007-0069-6

[59] Vargo, S.L. and Lusch, R.F. (2011) It’s All B2B...and Beyond: Toward a Systems Perspective of the Market. Industrial Marketing Management, 40, 181-187. http://dx.doi.org/10.1016/j.indmarman.2010.06.026

[60] Shannon, C.E. and Weaver, W. (1949) The Mathematical Theory of Communication. University of Illinois Press, Urbana.

[61] Forrester, J.W. (1989) The Beginning of System Dynamics. MIT System Dynamics Group Memo D-4165-1, Cambridge. 